\title{
Chest Compressions in the Delivery Room
}

\author{
Catalina Garcia-Hidalgo ${ }^{1,2}$ and Georg M. Schmölzer ${ }^{2,3, *(D)}$ \\ 1 Faculty of Science, University of Alberta, Edmonton, AB T5H 3V9, Canada; garciahi@ualberta.ca \\ 2 Centre for the Studies of Asphyxia and Resuscitation, Neonatal Research Unit, Royal Alexandra Hospital, \\ Edmonton, AB T5H 3V9, Canada \\ 3 Department of Pediatrics, University of Alberta, Edmonton, AB T5H 3V9, Canada \\ * Correspondence: georg.schmoelzer@me.com; Tel.: +1-780-735-4647
}

Received: 1 October 2018; Accepted: 26 December 2018; Published: 3 January 2019

\begin{abstract}
Annually, an estimated 13-26 million newborns need respiratory support and 2-3 million newborns need extensive resuscitation, defined as chest compression and $100 \%$ oxygen with or without epinephrine in the delivery room. Despite such care, there is a high incidence of mortality and neurologic morbidity. The poor prognosis associated with receiving chest compression alone or with medications in the delivery room raises questions as to whether improved cardiopulmonary resuscitation methods specifically tailored to the newborn could improve outcomes. This review discusses the current recommendations, mode of action, different compression to ventilation ratios, continuous chest compression with asynchronous ventilations, chest compression and sustained inflation optimal depth, and oxygen concentration during cardiopulmonary resuscitation.
\end{abstract}

Keywords: infants; newborn; neonatal resuscitation; chest compressions; delivery room

\section{Background}

Most newborn infants successfully make the transition from fetal to neonatal life without any help [1]. However, an estimated 10-20\% of newborns (13-26 million worldwide) need respiratory support [1], which remains the most critical step of neonatal resuscitation [2,3]. Furthermore, $0.1 \%$ of term infants and up to $15 \%$ of preterm infants (2-3 million worldwide) need extensive resuscitation [4-7], defined as chest compressions (CCs) and $100 \%$ oxygen $\left(\mathrm{O}_{2}\right)$ with or without epinephrine in the delivery room (DR). Despite such care, there is a high incidence of mortality and short-term neurologic morbidity [6-11]. The poor prognosis associated with receiving CC alone or with medications in the DR raises questions as to whether improved cardiopulmonary resuscitation (CPR) methods specifically tailored to the newborn could improve outcomes [12,13]. The inability to predict which newborns need CPR and the infrequent use of CPR in the DR have limited the ability of neonatologists to perform rigorous clinical studies aimed at determining the best method for delivering CC to newborn infants $[12,13]$.

\section{Current Recommendations}

The current neonatal resuscitation guidelines recommend to start CCs in a newborn infant if the heart rate remains $<60$ beats per minute despite adequate ventilation for $60 \mathrm{~s}$ [2,3]. CCs should be performed using the two thumb technique and a 3:1 compression to ventilation $(\mathrm{C}: \mathrm{V})$ ratio, which consists of 90 chest compressions and 30 inflations [2,3]. This approach is composed of 90 CCs and 30 inflations per minute, with a pause after every third CC to deliver one effective inflation. Inflations and CCs should be synchronized to avoid inadequate oxygen delivery during CCs [2,3]. Furthermore, there is an ongoing debate about how long resuscitation efforts after birth should continue if no heart rate can be detected [2,3]. Only very low quality evidence exists to support of refute this 
recommendation in infants with a gestational age of $\geq 36$ weeks and an Apgar score of 0 at 10 min. These data suggest that 75/129 infants will die before 22 months of age and 106/129 infants will either die or have moderate/severe neurodevelopmental impairment at 22 months of age [2,3]. Therefore, the current recommendations suggest that it is reasonable to stop resuscitation if a late-preterm or term infant has an Apgar score of 0 at $10 \mathrm{~min}$ with an undetectable heart rate. However, given the current evidence, the decision to continue or discontinue resuscitative efforts should be individualized [2,3].

The current recommendation is based on expert opinions and consensus rather than strong scientific evidence [2,3]. Rationales for using 3:1 C:V ratio include (i) a higher physiological heart rate of 120-160 beats/min, and (ii) higher breathing rates of 40-60 breaths/min in newborn infants compared to heart rate and breathing rates adults $[12,13]$. Ironically, the $3: 1 \mathrm{C}: \mathrm{V}$ ratio only provides $90 \mathrm{CCs} / \mathrm{min}$, which is considerably less than the normal newborn heart rate of $120-160$ beats $/ \mathrm{min}$. While the argument may be true that the 3:1 C:V ratio is used in an attempt to match the newborn heart rate and respiratory rate, in actuality, a 3:1 C:V ratio provides considerably lower compressions than the normal newborn heart rate, and, interestingly, is also lower than the recommended 100 compressions per minute in Advanced Cardiovascular Life Support (which is higher than the resting adult heart rate of $\sim 70$ beats $/ \mathrm{min}$ ). Furthermore, profound bradycardia or cardiac arrest in newborn infants is usually caused by hypoxia/asphyxia rather than primary cardiac compromise [12,14]; therefore, providing ventilation is more likely to be beneficial in neonatal CCs compared to adult CCs. However, the optimal CC approach to optimize coronary and cerebral perfusion while providing adequate ventilation of an asphyxiated newborn remains unknown [15].

\section{Mode of Action}

During chest compressions, the blood is pumped mechanically through the body until the myocardium becomes sufficiently oxygenated to improve function [16-23]. The generation of blood flow and blood expulsion from the ventricles during CCs is thought to occur by either direct compression of the heart between the sternum and vertebral column (cardiac pump theory) or phasic increases in intrathoracic pressure (thoracic pump theory). The "cardiac pump theory" postulates that CCs directly eject blood from the heart into the circulation with each compression [17]. In comparison, the "thoracic pump theory" states that a phasic increase in intrathoracic pressure produced by compression of the chest creates a pressure gradient between the arterial and venous compartment [21-23]. This pressure gradient then serves as the driving force for antegrade blood flow. Optimized CC has been demonstrated to generate $30 \%$ of normal organ perfusion, with preferential $(>50 \%)$ perfusion to the heart and brain [15].

\section{Using Different Compression to Ventilation Ratios}

The current recommendation of using a 3:1 C:V ratio is based on expert opinions and consensus rather than strong scientific evidence [2,3]. Animal studies using cardiac arrest induced by asphyxia in newborn piglets demonstrated that combining CCs with ventilations improves return of spontaneous circulation (ROSC) and neurological outcome at $24 \mathrm{~h}$ compared to ventilations or CCs alone [24]. Solevåg et al. performed a study investigating alternating nine CCs and three ventilations in asphyxiated piglets with cardiac arrest, with the hypothesis that nine CCs would generate higher diastolic blood pressure during CCs than only three CCs in a series [25]. However, increasing the number of CCs in a row should not be at the expense of ventilation, hence the ratio of CCs and ventilation was maintained at 3:1. The time to ROSC was similar between the two approaches (150 and $148 \mathrm{~s}$ for 3:1 and 9:3, respectively). In addition, there were no differences in diastolic blood pressure during CCs [25]. Similarly, C:V ratios of 3:1 and 15:2 were compared using the same model [26]. Although the 15:2 C:V ratio provided a higher mean CC rate per minute (75 vs. $58 \mathrm{CCs} / \mathrm{min}$ for 15:2 and 3:1, respectively), time to ROSC was similar between groups (median time of 195 and $150 \mathrm{~s}$ for 15:2 and 3:1, respectively) [26]. Most recently, Pasquin et al. compared 2:1, 3:1, and 4:1 C:V ratios during asphyxia-induced cardiac arrest in newborn piglets and reported no differences in the median 
(Interquartile range (IQR)) time to ROSC with 127 (82-210), 96 (88-126), and 119 (83-256) s, respectively ( $p=0.67$ between groups), similar oxygen requirements, and similar epinephrine administration between the groups [27]. Furthermore, Traub et al. resuscitated 2-3-week-old piglets after potassium chloride-induced cardiac arrest with $\mathrm{C}: \mathrm{V}$ ratios of 1:2, 1:3, 1:4, or 1:5 and reported no differences in time to ROSC [28]. Conclusively, these studies suggest that different $\mathrm{C}: \mathrm{V}$ ratios have similarly ROSC, mortality, and hemodynamic recovery. However, no study has examined short- or long-term neurological outcome, and therefore further studies are needed to address these shortcomings.

\section{Continuous Chest Compressions with Asynchronous Ventilations}

In both adult and pediatric advanced life support, continuous CCs with asynchronous ventilations $(\mathrm{CCaV})$ are recommended after a secure airway has been established $[16,17]$. In contrast, current neonatal resuscitation guidelines recommend using a coordinated $3: 1 \mathrm{C}: \mathrm{V}$ ratio if $\mathrm{CCs}$ are needed. However, our own observations show that even individuals experienced in resuscitation use $\mathrm{CCaV}$ during neonatal resuscitation in the delivery room, most likely due to increased stress [29]. Manikin studies reported higher ventilation rates with 3:1 C:V ratio during simulated CCs compared to higher $\mathrm{C}: \mathrm{V}$ ratios [30-32]. Consequently, the higher ventilation during 3:1 C:V ratio resulted in significantly higher minute ventilation of $191 \mathrm{~mL} / \mathrm{kg}$ compared to 140 and $77 \mathrm{~mL} / \mathrm{kg} / \mathrm{min}$ with 9:3 and 15:2 C:V ratios, respectively [33]. A further manikin study compared the 3:1 C:V ratio with CCaV using $90 \mathrm{CCs}$ and 30 non-synchronized inflations and reported similar tidal volume $\left(\mathrm{V}_{\mathrm{T}}\right)$ measurements of 6.4 and $5.6 \mathrm{~mL} / \mathrm{kg}$, respectively. However, minute ventilation was significantly higher in the CCaV group compared to the 3:1 ratio group (221 versus $191 \mathrm{~mL} / \mathrm{kg} / \mathrm{min}$, respectively) [33]. Schmölzer et al. compared the 3:1 C:V ratio with $\mathrm{CCaV}$ in a piglet model of neonatal asphyxia and reported similar median $\mathrm{V}_{\mathrm{T}}$ (14.7 versus $11.0 \mathrm{~mL} / \mathrm{kg}$ ) and minute ventilation ( 387 versus $275 \mathrm{~mL} / \mathrm{kg}$ ) [34]. However, there was a trend to reduced median time to ROSC (143 and $114 \mathrm{~s}$ for 3:1 ratio and CCaV, respectively) and survival (3/8 and 6/8, respectively) [34]. Most recently, Solevåg et al. compared the 3:1 C:V ratio and $\mathrm{CCaV}$ with either $21 \%$ or $100 \%$ oxygen and reported similar times to ROSC (heart rate $\geq 100 \mathrm{~min}^{-1}$ ) ranging from 75 to $592 \mathrm{~s}$ and mortality of 50-75\% between groups [35]. An argument of synchronized CPR is the potential interference of non-synchronized CC with $V_{T}$ delivery, hence impairment of oxygen delivery. However, the study by Schmölzer et al. observed $29 \%$ and $25 \%$ of manual inflations were similarly affected by CCs during $\mathrm{CCaV}$ and 3:1 C:V ratio CCs, respectively [34]. These studies suggest that a similar oxygen delivery can be achieved with coordinated CCs and ventilation at a ratio of $3: 1$ or $\mathrm{CCaV}$.

Furthermore, the studies by Schmölzer et al. and Solevåg et al. examined hemodynamic changes during $\mathrm{CCaV}$ and 3:1 C:V ratio CPR [34,35]. Solevåg et al. reported that immediately after ROSC, piglets resuscitated with $\mathrm{CCaV}$ had lower mean arterial blood pressure (at $15 \mathrm{~min}(p=0.05)$, but not at $4 \mathrm{~h}(p=0.20))$ [35]. In addition, the myocardial lactate was higher after CPR with CCaV compared to 3:1 C:V ratio CPR, with $1.1(0.8-1.2) \mathrm{mol} / \mathrm{mg}$ protein versus $2.1(1.3-2.3) \mathrm{mol} / \mathrm{mg}$ protein $(p=0.05)$, respectively [35]. In comparison, Schmölzer et al. reported no difference in the percentage changes from normoxic baseline of blood flow index in the pulmonary artery, the common carotid artery, the superior mesenteric artery, and the renal artery [34]. Furthermore, the mean systemic arterial pressure ( $31 \pm 5$ and $26 \pm 8 \mathrm{mmHg}$, respectively), mean pulmonary artery pressure (31 \pm 7 and $31 \pm 9 \mathrm{mmHg}$, respectively), central venous pressure (23 \pm 12 and $19 \pm 9 \mathrm{mmHg}$, respectively), and the mean systemic arterial pressure/mean pulmonary artery pressure ratio $(0.98 \pm 0.1$ and $0.82 \pm 0.2$, respectively) were similar between 3:1 C:V ratio and CCaV and CPR [34]. These studies suggest that $\mathrm{CCaV}$ and 3:1 C:V ratio have different effects on hemodynamics after ROSC.

\section{Predicting Success of Chest Compressions}

During neonatal resuscitation, it is impossible to different between infants who might survive and infants who do not survive [36]. Manley et al. showed videos of the resuscitation of 10 extremely premature infants (mean gestation 26 weeks) to a group of 17 attending neonatologists and 17 neonatal 
fellows to estimate the likelihood of survival to discharge for each infant at 3 time points: $20 \mathrm{~s}, 2 \mathrm{~min}$, and $5 \mathrm{~min}$ after birth [36]. The observers' ability to predict survival was poor: 0.61 (95\% CI: $0.54-0.67$ ) at $20 \mathrm{~s}, 0.59$ (95\% CI: 0.52-0.64) at $2 \mathrm{~min}$, and 0.61 (95\% CI: 0.55-0.67) at $5 \mathrm{~min}$ [36].

No study has assessed this in newborn infants requiring chest compressions in the delivery room. Furthermore, there are limited data on potential parameters to predict success. Chalak et al. reported that an end-tidal $\mathrm{CO}_{2}$ value of $14 \mathrm{mmHg}$ is a predictor for ROSC [37]. Similarly, Chandrasekharan et al. reported that an end-tidal $\mathrm{CO}_{2}$ threshold of $\geq 32 \mathrm{mmHg}$ was $100 \%$ sensitive and $97 \%$ specific to predicting ROSC in 12 near-term lambs [38]. In addition, Li et al. reported that surviving piglets have significant improved gas exchange and hemodynamics during CPR [39]. Indeed, Li et al. reported that end-tidal $\mathrm{CO}_{2}$, the partial pressure of exhaled $\mathrm{CO}_{2}\left(\mathrm{PECO}_{2}\right)$, and the volume of expired $\mathrm{CO}_{2}\left(\mathrm{VCO}_{2}\right)$ were significantly higher in surviving piglets compared to non-surviving piglets [39]. These studies suggest that end-tidal $\mathrm{CO}_{2}$ might be a clinical parameter to guide resuscitation efforts.

Unfortunately, data on hemodynamic parameters are lacking. Schmölzer et al. reported that hemodynamic parameters do not predict success in a post-transitional piglet model $[34,35]$. Similarly, a neonatal lamb asphyxia model with transitioning circulation reported that hemodynamic parameters do not predict success [40]. However, Vali et al. observed higher lactic acidosis, higher partial arterial $\mathrm{O}_{2}\left(\mathrm{PaO}_{2}\right)$, and lower partial arterial $\mathrm{CO}_{2}\left(\mathrm{PaCO}_{2}\right)$ in lambs who did not achieve ROSC, which might represent a state of inadequate tissue perfusion and/or mitochondrial dysfunction [40]. Furthermore, Wagner et al. compared hemodynamic parameters using a Millar catheter in surviving and non-surviving piglets [41]. Overall, there were no significant differences in hemodynamic parameters including end-diastolic and developed pressures, $\mathrm{dp} / \mathrm{dt} \mathrm{min}$, and $\mathrm{dp} / \mathrm{dt}$ max in surviving and non-surviving piglets [41]. Furthermore, the administration of epinephrine had no effect on heart rate or cardiac output in surviving and non-surviving piglets [41]. These studies suggest that further studies are needed to examine potential hemodynamic parameters that might predict ROSC.

\section{Optimal Depth}

In infants and neonates, current guidelines recommend external compression to a depth of approximately $33 \%$ of the anterior-posterior (AP) diameter of the chest, which is relatively greater than that recommended for adults (20\% of AP diameter) [2,3]. Studies in adult animals and humans show a positive correlation between receiving adequate CCs and improved outcomes [16]. Adequate CCs are important to achieve adequate cardiac output, however, over-compressing the chest, and therefore leaving inadequate residual chest depth during CC, has its own potential risks. Some of these risks may include rib fractures, cardiac contusion, and other thoracic injuries [12]. Despite the importance of delivering appropriate $\mathrm{CCs}$, adequate $\mathrm{CC}$ AP depth has not been rigorously evaluated in neonates.

Manikin studies compared the CC depth using C:V ratios of 3:1, 5:1, and 15:2 during two-minute simulated CPR [30]. Participants had higher and more consistent CC depth during 3:1 C:V, however, the $C C$ rate was lower in CCs with $C: V$ ratio of 3:1 compared to 15:2. In addition, the depth decay during CCs was significantly higher during 5:1 C:V and 15:2 C:V ratios compared to 3:1 C:V ratio [30]. A recent analysis of computed tomography scan images of neonates predicted better ejection fraction (EF) using one-third AP CC depth compared to one-quarter AP CC depth [42]. Furthermore, no subjects receiving the one-third AP CC depth were under-compressed (i.e., had a predicted $\mathrm{EF}<50 \%$ ), whereas $54 \%$ were predicted to be under-compressed at the one-quarter AP CC depth. The one-third AP compression depth was much less likely to meet criteria for predicted over-compression than one-half compression depth. This is similar to our own observations in that even individuals experienced at resuscitation do not achieve the required CC depth during neonatal CCs $[43,44]$. This is concerning, as a decrease in CC depth due to rescuer fatigue can potentially lead to reduced cardiac output and increased mortality. 


\section{Oxygen Concentration During CPR}

Oxygen $\left(\mathrm{O}_{2}\right)$ has been used in neonatal resuscitation for over 200 years [45]. Its use spread rapidly in response to reports of brain damage in infants who survived birth asphyxia. The inclusion of skin color in the Apgar score in 1965 further contributed to an increased use of $\mathrm{O}_{2}$ in the delivery room [45]. However, over the past decades, $100 \% \mathrm{O}_{2}$ during delivery room resuscitation has been questioned, as even a brief exposure of asphyxiated infants to $100 \% \mathrm{O}_{2}$ is associated with adverse effects [46-52]. Current neonatal resuscitation guidelines recommend $100 \%$ oxygen $\left(\mathrm{O}_{2}\right)$ during cardiopulmonary resuscitation (CPR) [2,3], however, the most effective $\mathrm{O}_{2}$ concentration during CPR remains controversial.

High concentrations of $\mathrm{O}_{2}$ delivery during CPR generate $\mathrm{O}_{2}$-free radicals, which play a major role in reperfusion/reoxygenation injury after asphyxia, especially to oxyregulatory tissues (e.g., myocardium). In addition, $100 \% \mathrm{O}_{2}$ exposure at birth has been associated with increased risk of neonatal mortality and childhood cancer [46,50]. It has been established that depressed infants (with respiratory depression from asphyxia) can be successfully resuscitated with room air, however, its effectiveness in infants with depressed circulation has not been proven. Indeed, several clinical trials and meta-analyses reported that $100 \% \mathrm{O}_{2}$ during initial mask ventilation at birth resulted in higher rates of (i) time to first breath $>3 \mathrm{~min}(28 / 284 \mathrm{vs}$. $60 / 321$ (relative risk (RR) ( $95 \%$ confidence Interval (CI)) $0.53(0.35-0.8))$ ), (ii) Apgar scores $<7$ at $5 \mathrm{~min}(71 / 288$ vs. 102/321 (RR (95\% CI) 0.78 (0.6-1.0))), and (iii) death (70/616 vs. $107 / 659$ (RR (95\% CI) $0.71(0.54-0.94)))$ compared with $21 \%$ $\mathrm{O}_{2}[48,49]$. The neonatal resuscitation guidelines have recognized this and recommend air instead of $100 \% \mathrm{O}_{2}$ during initial mask ventilation [2,3]. However, during CPR, the guidelines continue to recommend an increase to $100 \% \mathrm{O}_{2}[2,3]$.

Studies in asphyxiated term infants reported that $100 \% \mathrm{O}_{2}$ during respiratory support in the delivery room resulted in hyperoxemia $\left(\mathrm{PaO}_{2}, 126 \pm 22 \mathrm{mmHg}\right)$ and increased oxidative stress, but not higher cerebral oxygenation, which does not occur with $21 \%\left(\mathrm{PaO}_{2}, 72 \pm 7 \mathrm{mmHg}\right)$ [52]. Therefore, oxygen delivery during CPR must balance the prevention of tissue damage from $\mathrm{O}_{2}$ deprivation with the need to limit the adverse effects of oxidative stress damage from $\mathrm{O}_{2}$-free radicals $[51,52]$. Solevåg et al. resuscitated asphyxiated piglets with $21 \%$ vs. $100 \% \mathrm{O}_{2}$ and reported similar time to ROSC (ranging from 75 to 592 s) with very high mortality rates (50-75\%) in both groups [35]. Resuscitation with $21 \% \mathrm{O}_{2}$ was also associated with improved left ventricular stroke volume after ROSC and lower myocardial oxidative stress (median (IQR) Glutathione disulfide/Glutathione (GSSG/GSH) ratio 0.1 $(0.09-0.12)$ vs. $0.13(0.11-0.2) p=0.04)$ compared to $100 \% \mathrm{O}_{2}$ [35]. In addition, a recent meta-analysis of animal trials (no human studies were identified) reported eight animal studies ( $n=323$ animals) comparing various oxygen concentrations during chest compressions [53]. The pooled analysis showed no difference in mortality rates for animals resuscitated with air vs. $100 \%$ oxygen (risk ratio $\left.1.04(0.35,3.08), \mathrm{I}^{2}=0 \%, p=0.94\right)$. Time to ROSC was also similar between groups, with a mean difference of $-3.8(-29.7,22) \mathrm{s}\left(\mathrm{I}^{2}=0 \%, p=0.77\right)$. No differences in oxygen damage or adverse events were identified between air vs. $100 \%$ oxygen. These results suggest that air has similar time to ROSC and mortality as $100 \%$ oxygen during neonatal chest compressions. Randomized trials of air vs. $100 \%$ oxygen during neonatal chest compressions are warranted.

\section{Chest Compressions and Sustained Inflation}

An alternative approach of neonatal CCs has been recently described by Schmölzer et al. [54]. The group performed CCs during sustained inflation (SI) (with SI referring to constant high airway pressure while providing CCs) $(\mathrm{CC}+\mathrm{SI})$ in asphyxiated piglets and reported significantly improved systemic and regional hemodynamics, tidal volume delivery and minute ventilation, and time to ROSC compared to the 3:1 C:V ratio [54]. CC + SI had an improved recovery, with mean arterial pressure: 51 vs. $31 \mathrm{mmHg}$; pulmonary arterial pressure: 41 vs. $31 \mathrm{mmHg}$; mean minute ventilation: 936 vs. $623 \mathrm{~mL} / \mathrm{kg}$; and median time to ROSC: 38 vs. $143 \mathrm{~s}$, respectively, compared to the 3:1 C:V ratio [54]. In addition, during CC + SI, a constant lung recruitment and establishment of functional 
residual capacity was observed (a gain of $2.3 \mathrm{~mL} / \mathrm{kg} / \mathrm{CC}+\mathrm{SI}$ cycle) [55]. This improvement in $\mathrm{V}_{\mathrm{T}}$ led to better alveolar oxygen delivery and lung aeration. When using the $3: 1 \mathrm{C}: \mathrm{V}$ ratio, a cumulated loss of tidal volume of $4.5 \mathrm{~mL} / \mathrm{kg}$ occurred for each 3:1 C:V cycle [55]. This is concerning, as a loss in $\mathrm{V}_{\mathrm{T}}$ could cause lung derecruitment, which could hamper oxygenation and therefore ROSC.

Furthermore, the paper by Schmölzer et al. was the first description of passive $\mathrm{V}_{\mathrm{T}}$ delivery and passive ventilation during neonatal CCs [54,55]. During compression of the chest, volume is exhaled and during chest recoil, gas passively flows back into the lungs. The required distending pressure to achieve passive lung ventilation and adequate tidal volume delivery is $\sim 25 \mathrm{cmH}_{2} \mathrm{O}$, which correlated in cadaver piglets $(r=0.83, p<0.001)$, manikins $(r=0.98, p<0.001)$, and when combined (piglets + manikins) $(r=0.49, p<0.001)$ [56]. A similar observation was reported during chest recoil after a downward force was applied to the chest of infants undergoing surgery requiring general anesthesia [57]. Overall, the median (IQR) tidal volume generated was $2.4(0.8-4.0) \mathrm{mL} / \mathrm{kg}$ [57], which suggests that chest recoil generates a distending pressure-dependent tidal volume to allow passive ventilation during CCs. However, in the original study by Schmölzer et al., CCs were performed at a rate of $120 / \mathrm{min}$ in the CC + SI group, which is higher than the currently recommended CC rate of $90 / \mathrm{min}$, and this could have contributed to the improved outcomes [54]. Subsequently, we reported that, compared to the $3: 1 \mathrm{C}: \mathrm{V}$ ratio, $\mathrm{CC}+\mathrm{SI} 90 / \mathrm{min}$ resulted in a reduction in median (IQR) time to ROSC (34 (28-156) vs. 210 (72-300) s ( $p=0.05)$ ), less oxygen ( $3 / 8$ vs. 8/8 required $\left.100 \% \mathrm{O}_{2}, p=0.03\right)$, and $3 / 8$ vs. $6 / 8$ piglets received epinephrine $(p=0.32)$ during CCs [58]. Two further randomized piglet trials compared CC rates of $90 / \mathrm{min}$ vs. $120 /$ min during CC + SI and CC + SI with either $20 \mathrm{~s}$ or $60 \mathrm{~s}$ SI and reported similar time to ROSC, survival rates, and respiratory parameters $[59,60]$. More importantly, during CCs, carotid blood flow, mean arterial pressure, percent change in ejection fraction, and cardiac output were higher in the CC + SI 90/min group compared to CC + SI 120/min [59]. Similarly, Vali et al. reported that CC + SI is feasible in a transitional model of near-term lambs [61]. Most recently, a small pilot trial compared CC + SI and 3:1 C:V ratio CPR in nine preterm infants $<32$ weeks' gestation (CC + SI group $(n=5$; gestational age $24.6 \pm 1.3) ; 3: 1 \mathrm{C}: \mathrm{V}$ ratio group $(n=4$; $25.6 \pm 2.3$ ) group) [62]. Infants in the CC + SI group had significantly shorter mean \pm SD time to ROSC compared to those in the $3: 1 \mathrm{C}: \mathrm{V}$ ratio group ( $31 \pm 9$ vs. $138 \pm 72 \mathrm{~s}, p=0.011)$ [62]. However, the $\mathrm{SI}+$ CC group also had higher use of inotropes $(4 / 5 \mathrm{vs} .0 / 5)$, more deaths before discharge $(2 / 5 \mathrm{vs} .0 / 4)$, and increased necrotizing enterocolitis (3/5 vs. 1/4) compared to the 3:1 C:V group [62]. The lower diastolic blood pressures reported by Vali et al. [61] in the SI + CC group might have contributed to the higher inotrope use. Furthermore, a recent multicenter trial comparing sustained inflation vs. positive pressure ventilation as initial respiratory support [63] was terminated after 426 infants between $23^{+0}-26^{+6}$ were randomized. The interim analysis identified an increased mortality rate within $48 \mathrm{~h}$ after birth with an adjusted relative risk of sustained inflation vs. positive pressure ventilation of 4.73 (95\% CI: 1.4, 16.2). While this is concerning, the currently ongoing large multicenter cluster randomized trial comparing CC + SI with 3:1 C:V ratio during neonatal CPR in the delivery room (SURV1VE-trial) is only recruiting infant $>28$ weeks' gestation in order to reduce potential harm to this vulnerable population (https://clinicaltrials.gov/ct2/show/NCT02858583).

\section{Use of Animal Models}

Animal models are used to understand the science of normal and pathophysiological states in humans and have given rise to much of our current understanding of normal human biology and the mechanisms of disease $[13,64,65]$. To examine neonatal CPR, studies have used piglets and sheep models $[13,64,65]$. Piglets (domestic or miniature) are the most commonly used animal models for neonatal CC studies. Advantages of the piglet model include (i) distribution of coronary blood, (ii) blood supply to the conduction system, (iii) histologic appearance of the myocardium, and (iv) biochemical and metabolic responses to ischemic injury similar to human pathophysiology [13,64-66]. Disadvantages of the piglet model include (i) large inter-individual variation, making detection of significant differences caused by interventions challenging, and (ii) large litter size, which makes the development of 
transitional models challenging $[13,64,65]$. Sheep have been extensively used to study physiological changes and resuscitation techniques during perinatal transition [67-71]. Advantages of newborn sheep include (i) usefulness in examining lung mechanics during perinatal transition, (ii) large body mass and small litter size, and (iii) similar physiology and anatomy to human newborn infants $[13,64,65]$. Disadvantages of the sheep model include (i) large inter-individual variation, (ii) precocious maturation as compared to human infants of 44 weeks post-conceptual age, and (iii) V-shaped chest, which potentially affects the delivery of antero-posterior CCs compared to a human newborn $[13,64,65]$.

\section{Future Directions}

The current evidence for chest compressions in newborn infants is primarily based on animal data and expert opinions. There is a need for basic/translational evidence before high quality clinical trials can be performed. Before changes are made to guidelines, more studies are needed that show how CC protocols vary among and effect rescuers. Additionally, studies must include long-term neurodevelopmental outcomes in order to determine the possible long-term effects of neonatal CPR.

\section{Conclusions}

Successful cardiopulmonary resuscitation from cardiac arrest requires the delivery of high-quality chest compressions encompassing several factors including optimal compression:ventilation ratio, depth of chest compression, and oxygen concentration during cardiopulmonary resuscitation. Clinical trials in this area are urgently needed.

Author Contributions: Conception and design: G.M.S.; Collection and assembly of data: G.M.S., C.G.H.; Analysis and interpretation of the data: G.M.S., C.G.H.; Drafting of the article: G.M.S., C.G.H.; Critical revision of the article for important intellectual content: G.M.S., C.G.H.; Final approval of the article: G.M.S., C.G.H.

Funding: We would like to thank the public for donating money to our funding agencies: C.G.H. is a recipient of the Office of the Provost and VP (Academic) Summer Student Award, Faculty of Medicine and Dentistry, University of Alberta. G.M.S. is a recipient of the Heart and Stroke Foundation/University of Alberta Professorship of Neonatal Resuscitation, a National New Investigator of the Heart and Stroke Foundation Canada, and an Alberta New Investigator of the Heart and Stroke Foundation Alberta. This research was supported by a Grant from the SickKids Foundation in partnership with the Canadian Institutes of Health Research (CIHR-Institute of Human Development, Child and Youth Health (IHDCYH)), New Investigator Research Grant Program (Grant number-No. NI17-033), a Grant-in-Aid from the Heart and Stroke Foundation Canada (Grant Number: G-15-0009284), and a Women and Children's Health Research Institute grant through the generous support of the Stollery Children's Hospital Foundation.

Conflicts of Interest: The authors declare no conflict of interest.

\section{Abbreviations/Nomenclature}

\begin{tabular}{ll}
\hline $\mathrm{C}: \mathrm{V}$ ratio & Compression to ventilation ratio \\
$\mathrm{CC}$ & Chest compression \\
$\mathrm{CCaV}$ & Continuous chest compressions with asynchronous ventilations \\
$\mathrm{CPP}$ & Coronary perfusion pressure \\
$\mathrm{CPR}$ & Cardiopulmonary resuscitation \\
$\mathrm{DR}$ & Delivery room \\
PPV & Positive pressure ventilation \\
ROSC & Return of spontaneous circulation \\
SI & Sustained inflation \\
\hline
\end{tabular}

\section{References}

1. Aziz, K.; Chadwick, M.; Baker, M.; Andrews, W. Ante- and intra-partum factors that predict increased need for neonatal resuscitation. Resuscitation 2008, 79, 444-452. [CrossRef] [PubMed] 
2. Perlman, J.M.; Wyllie, J.P.; Kattwinkel, J.; Wyckoff, M.H.; Aziz, K.; Guinsburg, R.; Kim, H.S.; Liley, H.G.; Mildenhall, L.; Simon, W.M. Part 7: Neonatal resuscitation: 2015 international consensus on cardiopulmonary resuscitation and emergency cardiovascular care science with treatment recommendations. Pediatrics 2015, 136, S204-S241. [CrossRef] [PubMed]

3. Wyckoff, M.H.; Aziz, K.; Escobedo, M.B.; Kapadia, V.S.; Kattwinkel, J.; Perlman, J.M.; Simon, W.M.; Weiner, G.M.; Zaichkin, J.G. Part 13: Neonatal resuscitation 2015 American heart association guidelines update for cardiopulmonary resuscitation and emergency cardiovascular care (reprint). Pediatrics 2015, 136, S196-S218. [CrossRef] [PubMed]

4. Barber, C.A.; Wyckoff, M.H. Use and efficacy of endotracheal versus intravenous epinephrine during neonatal cardiopulmonary resuscitation in the delivery room. Pediatrics 2006, 118, 1028-1034. [CrossRef] [PubMed]

5. Harrington, D.J.; Redman, C.W.; Redman, C.W.; Moulden, M.; Greenwood, C.E.; Greenwood, C.E. The long-term outcome in surviving infants with Apgar zero at $10 \mathrm{~min}$ : A systematic review of the literature and hospital-based cohort. Am. J. Obstet. Gynecol. 2007, 196, e1-e5. [CrossRef] [PubMed]

6. Shah, P.S.; Shah, P.; Tai, K.F.Y. Chest compression and/or epinephrine at birth for preterm infants $<32$ weeks gestational age: Matched cohort study of neonatal outcomes. J. Perinatol. 2009, 29, 693-697. [CrossRef] [PubMed]

7. Soraisham, A.S.; Lodha, A.K.; Singhal, N.; Yang, J.; Lee, S.K.; Shah, P.S.; Aziz, K. Neonatal outcomes following extensive cardiopulmonary resuscitation in the delivery room for infants born at less than 33 weeks gestational age. Resuscitation 2014, 85, 238-243. [CrossRef] [PubMed]

8. Handley, S.C.; Handley, S.C.; Sun, Y.; Sun, Y.; Wyckoff, M.H.; Lee, H.C. Outcomes of extremely preterm infants after delivery room cardiopulmonary resuscitation in a population-based cohort. J. Perinatol. 2015, 35, 379-383. [CrossRef]

9. Frontanes, A.; García-Fragoso, L.; García, I.; Rivera, J.; Valcárcel, M. Outcome of very-low-birth-weight infants who received epinephrine in the delivery room. Resuscitation 2011, 82, 427-430. [CrossRef]

10. Wyckoff, M.H.; Perlman, J.M. Cardiopulmonary resuscitation in very low birth weight infants. Pediatrics 2000, 106, 618-620. [CrossRef]

11. Shah, P.S. Extensive cardiopulmonary resuscitation for VLBW and ELBW infants: A systematic review and meta-analyses. J. Perinatol. 2009, 29, 655-661. [CrossRef] [PubMed]

12. Solevåg, A.; Cheung, P.-Y.; O’Reilly, M.; Schmölzer, G.M. A review of approaches to optimise chest compressions in the resuscitation of asphyxiated newborns. Arch. Dis. Child. Fetal Neonatal 2016, 101, F272-F276. [CrossRef] [PubMed]

13. Solevåg, A.; Schmölzer, G.M. Optimal chest compression rate and compression to ventilation ratio in delivery room resuscitation: Evidence from newborn piglets and neonatal manikins. Front. Pediatr. 2017, 5, 3. [CrossRef] [PubMed]

14. Solevåg, A.; Cheung, P.-Y.; Schmölzer, G.M. Chest compressions and ventilation in delivery room resuscitation. NeoReviews 2014, 15, e396-e402. [CrossRef]

15. Wyckoff, M.H.; Berg, R.A. Optimizing chest compressions during delivery-room resuscitation. Semin. Fetal Neonatal Med. 2008, 13, 410-415. [CrossRef]

16. Halperin, H.H.; Tsitlik, J.; Guerci, A.D.; Mellits, E.D.; Levin, H.R.; Shi, A.Y.; Chandra, N.; Weisfeldt, M.L. Determinants of blood flow to vital organs during cardiopulmonary resuscitation in dogs. Circulation 1986, 73, 539-550. [CrossRef]

17. Rudikoff, M.; Maughan, W.L.; Effron, M.; Fresson, J.; Weisfeldt, M.L. Mechanisms of blood flow during cardiopulmonary resuscitation. Circulation 1980, 61, 345-352. [CrossRef]

18. Higano, S.T.; Oh, J.K.; Ewy, G.A.; Seward, J.B. The mechanism of blood flow during closed chest cardiac massage in humans: Transesophageal echocardiographic observations. Mayo. Clin. Proc. 1990, 65, 1432-1440. [CrossRef]

19. Berg, R.A.; Sanders, A.B.; Kern, K.B.; Hilwig, R.W.; Heidenreich, J.W.; Porter, M.E.; Ewy, G.A. Adverse hemodynamic effects of interrupting chest compressions for rescue breathing during cardiopulmonary resuscitation for ventricular fibrillation cardiac arrest. Circulation 2001, 104, 2465-2470. [CrossRef]

20. Kern, K.B.; Hilwig, R.W.; Berg, R.A.; Sanders, A.B.; Ewy, G.A. Importance of continuous chest compressions during cardiopulmonary resuscitation: Improved outcome during a simulated single lay-rescuer scenario. Circulation 2002, 105, 645-649. [CrossRef] 
21. Chandra, N.; Weisfeldt, M.L.; Tsitlik, J.; Vaghaiwalla, F.; Snyder, L.D.; Hoffecker, M.; Rudikoff, M.T. Augmentation of carotid flow during cardiopulmonary resuscitation by ventilation at high airway pressure simultaneous with chest compression. Am. J. Cardiol. 1981, 48, 1053-1063. [CrossRef]

22. Chandra, N.; Beyar, R.; Halperin, H.H.; Tsitlik, J.; Wurmb, E.; Rayburn, B.; Guerci, A.D.; Weisfeldt, M.L. Vital organ perfusion during assisted circulation by manipulation of intrathoracic pressure. Circulation 1991, 84, 279-286. [CrossRef]

23. Koehler, R.C.; Tsitlik, J.; Chandra, N.; Guerci, A.D.; Rogers, M.C.; Weisfeldt, M.L. Augmentation of cerebral perfusion by simultaneous chest compression and lung inflation with abdominal binding after cardiac arrest in dogs. Circulation 1983, 67, 266-275. [CrossRef] [PubMed]

24. Berg, R.A.; Hilwig, R.W.; Kern, K.B.; Ewy, G.A. "Bystander” chest compressions and assisted ventilation independently improve outcome from piglet asphyxial pulseless "Cardiac Arrest". Circulation 2000, 101, 1743-1748. [CrossRef] [PubMed]

25. Solevåg, A.; Dannevig, I.; Wyckoff, M.H.; Saugstad, O.D.; Nakstad, B. Extended series of cardiac compressions during CPR in a swine model of perinatal asphyxia. Resuscitation 2010, 81, 1571-1576. [CrossRef] [PubMed]

26. Solevåg, A.; Dannevig, I.; Wyckoff, M.H.; Saugstad, O.D.; Nakstad, B. Return of spontaneous circulation with a compression: Ventilation ratio of 15:2 versus 3:1 in newborn pigs with cardiac arrest due to asphyxia. Arch. Dis. Child. Fetal Neonatal 2011, 96, F417-F421. [CrossRef]

27. Pasquin, M.P.; Cheung, P.-Y.; Patel, S.; Lu, M.; Lee, T.-F.; Wagner, M.; O’Reilly, M.; Schmölzer, G.M. Comparison of different compression to ventilation ratios (2:1, 3:1, and 4:1) during cardiopulmonary resuscitation in a porcine model of neonatal asphyxia. Neonatology 2018, 114, 37-45. [CrossRef]

28. Traub, E.; Dick, W.; Lotz, P.; Lindner, K.H.; Engels, K. Investigations on neonatal cardiopulmonary reanimation using an animal model. J. Perinat. Med. 1983, 11, 103-113. [CrossRef]

29. Li, E.S.-S.; Cheung, P.-Y.; Pichler, G.; Aziz, K.; Schmölzer, G.M. Respiratory function and near infrared spectroscopy recording during cardiopulmonary resuscitation in an extremely preterm newborn. Neonatology 2014, 105, 200-204. [CrossRef]

30. Hemway, R.J.; Christman, C.; Perlman, J.M. The 3:1 is superior to a 15:2 ratio in a newborn manikin model in terms of quality of chest compressions and number of ventilations. Arch. Dis. Child. Fetal Neonatal 2013, 98, F42-F45. [CrossRef]

31. Srikantan, S.K.; Berg, R.A.; Cox, T.; Tice, L. Effect of one-rescuer compression/ventilation ratios on cardiopulmonary resuscitation in infant, pediatric, and adult manikins. Pediatr. Crit. Care Med. 2005, 6, 293-297. [CrossRef] [PubMed]

32. Whyte, S.D.; Sinha, A.K.; Wyllie, J.P. Neonatal resuscitation-A practical assessment. Resuscitation 1999, 40, 21-25. [CrossRef]

33. Solevåg, A.; Madland, J.M.; Gjærum, E.; Nakstad, B. Minute ventilation at different compression to ventilation ratios, different ventilation rates, and continuous chest compressions with asynchronous ventilation in a newborn manikin. Scand. J. Trauma Resusc. Emerg. Med. 2012, 20, 73. [CrossRef]

34. Schmölzer, G.M.; O’Reilly, M.; LaBossiere, J.; Lee, T.-F.; Cowan, S.; Nicoll, J.; Bigam, D.L.; Cheung, P.Y. 3:1 compression to ventilation ratio versus continuous chest compression with asynchronous ventilation in a porcine model of neonatal resuscitation. Resuscitation 2014, 85, 270-275. [CrossRef] [PubMed]

35. Solevåg, A.; Schmölzer, G.M.; O’Reilly, M.; Lu, M.; Lee, T.-F.; Hornberger, L.K.; Nakstad, B.; Cheung, P.Y. Myocardial perfusion and oxidative stress after $21 \%$ vs. $100 \%$ oxygen ventilation and uninterrupted chest compressions in severely asphyxiated piglets. Resuscitation 2016, 106, 7-13. [CrossRef] [PubMed]

36. Manley, B.J.; Dawson, J.A.; Kamlin, C.O.F.; Donath, S.; Morley, C.J.; Davis, P.G. Clinical assessment of extremely premature infants in the delivery room is a poor predictor of survival. Pediatrics 2010, 125, e559-e564. [CrossRef] [PubMed]

37. Chalak, L.F.; Barber, C.A.; Hynan, L.; Garcia, D.; Christie, L.; Wyckoff, M.H. End-tidal $\mathrm{CO}_{2}$ detection of an audible heart rate during neonatal cardiopulmonary resuscitation after asystole in asphyxiated piglets. Pediatr. Res. 2011, 69, 401-405. [CrossRef]

38. Chandrasekharan, P.; Vali, P.; Rawat, M.; Mathew, B.; Gugino, S.F.; Koenigsknecht, C.; Helman, J.; Nair, J.; Berkelhamer, S.; Lakshminrusimha, S. Continuous capnography monitoring during resuscitation in a transitional large mammalian model of asphyxial cardiac arrest. Pediatr. Res. 2017, 81, 898-904. [CrossRef] 
39. Li, E.S.-S.; Cheung, P.-Y.; O’Reilly, M.; LaBossiere, J.; Lee, T.-F.; Cowan, S.; Bigam, D.L.; Schmölzer, G.M. Exhaled $\mathrm{CO}_{2}$ parameters as a tool to assess ventilation-perfusion mismatching during neonatal resuscitation in a swine model of neonatal asphyxia. PLoS ONE 2016, 11, e0146524. [CrossRef]

40. Vali, P.; Chandrasekharan, P.; Rawat, M.; Gugino, S.F.; Koenigsknecht, C.; Helman, J.; Mathew, B.; Berkelhamer, S.; Nair, J.; Wyckoff, M.; et al. Hemodynamics and gas exchange during chest compressions in neonatal resuscitation. PLOS ONE 2017, 12, e0176478. [CrossRef]

41. Wagner, M.; Cheung, P.-Y.; Li, E.S.-S.; Lee, T.-F.; Lu, M.; Olischar, M.; O’Reilly, M.; Schmölzer, G.M. Effects of epinephrine on hemodynamic changes during cardiopulmonary resuscitation in a neonatal piglet model. Pediatr. Res. 2018, 83, 897-903. [CrossRef] [PubMed]

42. Meyer, A.; Nadkarni, V.; Pollock, A.; Babbs, C.; Nishisaki, A.; Braga, M.; Berg, R.A.; Ades, A. Evaluation of the neonatal resuscitation program's recommended chest compression depth using computerized tomography imaging. Resuscitation 2010, 81, 544-548. [CrossRef] [PubMed]

43. Cheung, P.-Y.; Li, E.S.-S.; Aziz, K.; O’Reilly, M.; Fu, B.; Zheng, B. Quantifying force application to a newborn manikin during simulated cardiopulmonary resuscitation. J. Mater. Fetal Neonatal Med. 2016, 29, 1770-1772.

44. Li, E.S.-S.; Cheung, P.-Y.; O’Reilly, M.; Aziz, K.; Schmölzer, G.M. Rescuer fatigue during simulated neonatal cardiopulmonary resuscitation. J. Perinatol. 2015, 35, 142-145. [CrossRef]

45. Obladen, M. History of neonatal resuscitation-Part 2: Oxygen and other drugs. Neonatology 2009, 95, 91-96. [CrossRef] [PubMed]

46. Spector, L.G.; Klebanoff, M.A.; Feusner, J.H.; Georgieff, M.K.; Ross, J.A. Childhood cancer following neonatal oxygen supplementation. J. Pediatr. 2005, 147, 27-31. [CrossRef]

47. Vento, M.; Saugstad, O.D. Oxygen supplementation in the delivery room: Updated information. J. Pediatr. 2011, 158, e5-e7. [CrossRef] [PubMed]

48. Tan, A.; Schulze, A.; O'Donnell, C.P.F.; Davis, P.G. Air versus oxygen for resuscitation of infants at birth. Cochrane Database Syst. Rev. 2005, 2, CD002273. [CrossRef]

49. Davis, P.G.; Tan, A.; O'Donnell, C.P.F.; Schulze, A. Resuscitation of newborn infants with 100\% oxygen or air: A systematic review and meta-analysis. Lancet 2004, 364, 1329-1333. [CrossRef]

50. Naumburg, E.; Bellocco, R.; Cnattingius, S.; Jonzon, A.; Ekbom, A. Supplementary oxygen and risk of childhood lymphatic leukaemia. Acta Paediatr. 2002, 91, 1328-1333. [CrossRef]

51. Vento, M.; Asensi, M.; Sastre, J.; Lloret, A.; García-Sala, F.; Miñana, J.B.; Viña, J. Hyperoxemia caused by resuscitation with pure oxygen may alter intracellular redox status by increasing oxidized glutathione in asphyxiated newly born infants. Semin. Perinatol. 2002, 26, 406-410. [CrossRef] [PubMed]

52. Vento, M.; Asensi, M.; Sastre, J.; Lloret, A.; García-Sala, F.; Viña, J. Oxidative stress in asphyxiated term infants resuscitated with 100\% oxygen. J. Pediatr. 2003, 142, 240-246. [CrossRef] [PubMed]

53. Garcia-Hidalgo, C.; Cheung, P.-Y.; Solevåg, A.; Vento, M.; O’Reilly, M.; Saugstad, O.D.; Schmolzer, G. A review of oxygen use during chest compressions in newborns. Front. Pediatr. 2018, 6, 1-7. [CrossRef]

54. Schmölzer, G.M.; O’Reilly, M.; LaBossiere, J.; Lee, T.-F.; Cowan, S.; Qin, S.; Bigam, D.L.; Cheung, P.Y. Cardiopulmonary resuscitation with chest compressions during sustained inflations: A new technique of neonatal resuscitation that improves recovery and survival in a neonatal porcine model. Circulation 2013, 128, 2495-2503. [CrossRef] [PubMed]

55. Li, E.S.-S.; Cheung, P.-Y.; O'Reilly, M.; Schmölzer, G.M. Change in tidal volume during cardiopulmonary resuscitation in newborn piglets. Arch. Dis. Child. Fetal Neonatal 2015, 100, F530-F533. [CrossRef] [PubMed]

56. Solevåg, A.; Lee, T.-F.; Lu, M.; Schmölzer, G.M.; Cheung, P.-Y. Tidal volume delivery during continuous chest compressions and sustained inflation. Arch. Dis. Child. Fetal Neonatal 2017, 102, F85-F87. [CrossRef]

57. Tsui, B.C.H.; Horne, S.; Tsui, J.; Corry, G.N. Generation of tidal volume via gentle chest pressure in children over one year old. Resuscitation 2015, 92, 148-153. [CrossRef] [PubMed]

58. Li, E.S.-S.; Görens, I.; Cheung, P.-Y.; Lee, T.-F.; Lu, M.; O’Reilly, M.; Schmölzer, G.M. Chest compressions during sustained inflations improve recovery when compared to a 3:1 compression: Ventilation ratio during cardiopulmonary resuscitation in a neonatal porcine model of asphyxia. Neonatology 2017, 112, 337-346. [CrossRef] [PubMed]

59. Li, E.S.-S.; Cheung, P.-Y.; Lee, T.-F.; Lu, M.; O’Reilly, M.; Schmölzer, G.M. Return of spontaneous circulation is not affected by different chest compression rates superimposed with sustained inflations during cardiopulmonary resuscitation in newborn piglets. PLoS ONE 2016, 11, e0157249. [CrossRef] [PubMed] 
60. Mustofa, J.; Cheung, P.-Y.; Patel, S.; Lee, T.-F.; Lu, M.; Pasquin, M.P.; O’Reilly, M.; Schmölzer, G.M. Effects of different durations of sustained inflation during cardiopulmonary resuscitation on return of spontaneous circulation and hemodynamic recovery in severely asphyxiated piglets. Resuscitation 2018, 129, 82-89. [CrossRef] [PubMed]

61. Vali, P.; Chandrasekharan, P.; Rawat, M.; Gugino, S.F.; Koenigsknecht, C.; Helman, J.; Mathew, B.; Berkelhamer, S.; Nair, J.; Lakshminrusimha, S. Continuous chest compressions during sustained inflations in a perinatal asphyxial cardiac arrest lamb model. Pediatr. Crit. Care Med. 2017, 18, e370-e377. [CrossRef] [PubMed]

62. Schmölzer, G.M.; O’Reilly, M.; Fray, C.; van Os, S.; Cheung, P.-Y. Chest compression during sustained inflation versus 3:1 chest compression:ventilation ratio during neonatal cardiopulmonary resuscitation: A randomised feasibility trial. Arch. Dis. Child. Fetal Neonatal 2018, 103, F455-F460. [CrossRef] [PubMed]

63. Foglia, E.E.; Owen, L.S.; Thio, M.; Ratcliffe, S.J.; Lista, G.; te Pas, A.; Hummler, H.; Nadkarni, V.; Ades, A.; Posencheg, M.; et al. Sustained aeration of infant lungs (SAIL) trial: Study protocol for a randomized controlled trial. Trials 2015, 16, 187-189. [CrossRef] [PubMed]

64. Solevåg, A.L.; Cheung, P.Y.; Lie, H.; O’Reilly, M.; Aziz, K.; Nakstad, B.; Schmölzer, G.M. Chest compressions in newborn animal models: A review. Resuscitation 2015, 96, 151-155. [CrossRef]

65. Hooper, S.B.; te Pas, A.B.; Polglase, G.R.; Wyckoff, M.H. Animal models in neonatal resuscitation research: What can they teach us? Semin. Fetal Neonatal Med. 2018, 23, 300-305. [CrossRef] [PubMed]

66. Varvarousi, G.; Johnson, E.O.; Goulas, S.; Agrogiannis, G.; Valsamakis, N.; Perrea, D.; Stefanadis, C.; Papadimitriou, L.; Xanthos, T. Combination pharmacotherapy improves neurological outcome after asphyxial cardiac arrest. Resuscitation 2012, 83, 527-532. [CrossRef]

67. Sobotka, K.; Hooper, S.B.; Allison, B.J.; Davis, P.G.; Morley, C.J.; Moss, T.J.M. An initial sustained inflation improves the respiratory and cardiovascular transition at birth in preterm lambs. Pediatr. Res. 2011, 70, 56-60. [CrossRef] [PubMed]

68. Sobotka, K.S.; Morley, C.; Ong, T.; Polglase, G.R.; Aridas, J.D.; Miller, S.L.; Schmölzer, G.M.; Klingenberg, C.; Moss, T.J.; Jenkin, G.; et al. Circulatory responses to asphyxia differ if the asphyxia occurs in utero or ex utero in near-term lambs. PLoS ONE 2014, 9, e112264. [CrossRef] [PubMed]

69. Sobotka, K.; Polglase, G.R.; Schmölzer, G.M.; Davis, P.G.; Klingenberg, C.; Hooper, S.B. Effects of chest compressions on cardiovascular and cerebral hemodynamics in asphyxiated near-term lambs. Pediatr. Res. 2015, 78, 395-400. [CrossRef]

70. Dargaville, P.A.; Lavizzari, A.; Padoin, P.; Black, D.; Zonneveld, E.; Perkins, E.; Sourial, M.; Rajapaksa, A.E.; Davis, P.G.; Hooper, S.B.; et al. An authentic animal model of the very preterm infant on nasal continuous positive airway pressure. Intensive Care Med. Exp. 2015, 3, 1-12. [CrossRef]

71. Klingenberg, C.; Sobotka, K.S.; Ong, T.; Allison, B.J.; Schmölzer, G.M.; Moss, T.J.; Polglase, G.R.; Dawson, J.A.; Davis, P.G.; Hooper, S.B. Effect of sustained inflation duration; resuscitation of near-term asphyxiated lambs. Arch. Dis. Child. Fetal Neonatal 2013, 98, F222-F227. [CrossRef] [PubMed]

(C) 2019 by the authors. Licensee MDPI, Basel, Switzerland. This article is an open access article distributed under the terms and conditions of the Creative Commons Attribution (CC BY) license (http:// creativecommons.org/licenses/by/4.0/). 